\title{
Informing Severely III Patients: Needs, Shortcomings and Strategies for Improvement
}

\author{
Barbara Strohbuecker $^{\mathrm{a}, \mathrm{c}}$ Jan Gaertner ${ }^{\mathrm{b}, \mathrm{c}}$ Stephanie Stock ${ }^{\mathrm{a}}$ \\ anstitute for Health Economics and Clinical Epidemiology, \\ ${ }^{b}$ Department for Palliative Medicine, Clinical Trials Center Cologne BMBF 01KN0706, \\ ${ }^{\circ}$ Center for Integrated Oncology Cologne Bonn, University Hospital of Cologne, Germany
}

\author{
Keywords \\ Patient information - Communication - Palliative care . \\ Early integration - Advanced cancer - Shared decision- \\ making
}

\section{Summary}

The scope of palliative care has expanded gradually over the last decade. Provision of palliative care is not restricted to the last months of life as in some out-dated concepts. It addresses the needs of severely ill patients in all care settings (in- and outpatients, home care, hospices). Particularly in the last years, the value of integrating palliative care early in the disease trajectory of life-threatening and incurable diseases has become increasingly acknowledged. In order for patients to fully benefit from the concept of early integration of palliative care, they need to be provided with information tailored to their disease trajectory. For example, patients and relatives need to know how symptoms such as pain, depression, fatigue, breathlessness, or anxiety can be alleviated. The patients' knowledge and understanding will support the coping process, improve comfort and enhance patient participation and autonomy. Since information needs are highly individual and vary throughout the course of the disease, an interactive approach of assessing the patients' needs and responding to them adequately is mandatory. In this article, the information needs of advanced cancer patients and their families are explained, shortcomings of the present information concepts are discussed, and an integrative approach to responding to patients' information needs throughout the care pathway is advocated.

\section{Schlüsselwörter}

Patienteninformation - Kommunikation - Palliative Versorgung · Frühe Integration · Fortgeschrittener Krebs . Gemeinsame Entscheidungsfindung

\section{Zusammenfassung}

Das Verständnis von Palliative Care hat sich im letzten Jahrzehnt gewandelt und erweitert. Verglichen mit älteren, mittlerweile überholten Konzepten sollte sich Palliative Care nicht auf die Betreuung von stationären Patienten in den letzten Lebensmonaten beschränken. Vielmehr sollte sie dezidiert medizinische sowie psychosoziale Bedürfnisse von schwer kranken Patienten in allen Behandlungssettings (stationär, ambulant, häuslich, Hospiz) berücksichtigen und den Patienten frühzeitig im Krankheitsverlauf angeboten werden. Das Potenzial dieser "early integration of palliative care" bei lebensbedrohlichen bzw. nicht heilbaren Erkrankungen findet auch in Deutschland zunehmend Anerkennung. Um sicherzustellen, dass Patienten die therapeutischen Möglichkeiten von Palliative Care optimal ausschöpfen können, benötigen sie und ihre Familien ausreichend Informationen. Zum Beispiel sollten sie wissen, was gegen belastende Symptome wie Schmerz, Depression, Erschöpfung, Luftnot oder Angst getan werden kann. Dieses Wissen unterstützt den Coping-Prozess, fördert das subjektive Wohlbefinden, gibt Sicherheit und verbessert die Partizipation und Patientenautonomie deutlich. Da die Informationsbedürfnisse individueller Natur sind und im Verlaufe der Erkrankung variieren, ist eine interaktive Herangehensweise notwendig, um die Bedürfnisse einschätzen und individuell auf sie reagieren zu können. In diesem Artikel stellen wir die Informationsbedürfnisse von schwer betroffenen Krebspatienten sowie ihren Familien dar und stellen einen integrativen Ansatz für die individuelle und zielgerichtete Patienteninformation sowie deren Integration in den Behandlungspfad vor.

\section{KARGER \\ Fax +497614520714 \\ Information@Karger.de}

www.karger.com (c) 2011 S. Karger GmbH, Freiburg

$1661-3791 / 11 / 0061-0008 \$ 38.00 / 0$

Accessible online at:

www.karger.com/brc
Barbara Strohbücker

Centrum für Integrierte Onkologie, Klinik für Innere Medizin I, Hs. 16 Universitätsklinikum Köln

Kerpenerstr. 62, 50924 Köln, Germany

Tel. +49 221 478-97258, Fax -89051

barbarastrohbuecker@uk-koeln.de 


\section{Introduction}

Dealing with severe illness is challenging for both patients and families. Many questions and uncertainties arise concerning emotional, physical, social, spiritual and technical issues. Especially in advanced stages of cancer, the patient is highly vulnerable and prone to lose self-confidence and control. Providing personalized information for patients through the cancer care continuum facilitates the coping process, improves patient comfort and enhances patient choice. However, information needs often remain unmet [1-4], resulting in unrelieved symptoms and distress and unnecessary hospitalizations [5, 6]. In particular, patients report substantial information deficits on therapeutic options, goals of treatment, impact of cancer on daily life, and management of symptoms of the disease $[3,6,7]$. Tracking down the necessary and relevant information is challenging for most patients although there is an abundant choice of printed and online information that has to be assessed [8]. Additionally, the multidisciplinary approach of cancer care and its specialization and fragmentation bear the risk of discontinuity as well as lack of and inconsistency of patient information [9]. In this article, we point out information needs of severely ill cancer patients and their families, discuss shortcomings in meeting information needs and present an integrative approach to responding to patient information needs.

\section{Information Needs}

\section{Content: How Many Details Are Requested?}

Many studies report that patients suffering from cancer generally want to be kept well informed about treatment options and the progress of their illness, be it positive or negative [1013]. This does not imply that full disclosure of information at any time is appropriate: In stressful situations, some patients may prefer to avoid certain information, as has been reported by recently diagnosed patients [14] and by patients with poor prognosis $[2,15,16]$. Both seeking information and avoiding it are strategies to cope with the cancer experience. Coping describes the dynamic process of dealing with a demanding situation and can be either satisfactory or unsatisfactory [17]. The outcome of coping depends (a) on the individual's judgment of the situation and (b) his appraisal of resources he can use to adapt and reestablish equilibrium [17]. Knowledge can foster successful coping as the patient may (a) appraise a situation as less threatening because he knows what to expect and/or (b) sees an option for affecting the outcome. Information can help people to feel in control, to reduce fears and to manage daily life. However, if the message is too threatening and little can be done to influence it, e.g. when therapy fails and a malignant disease progresses, the patient and his family may not be ready to bear it right away but need time and emotional support to accept it [18]. Information needs are context dependent and vary throughout the cancer care continuum and between individuals [4, 18-22]. What patients want to know does not necessarily correspond to what health care professionals think they want to know [23-25]. The challenge for health care professionals is to find out the patient's actual information preferences and to respond adequately, and not to base their information on personal assumptions.

Uncertainty about the future is very stressful for the patient. Therefore, in advanced disease, information on the course of the disease, the prognosis and on therapeutic options to influence progression is a key issue for severely ill patients $[2,26]$ and their caregivers $[2,18]$. Being informed on what to expect can reassure family members while their perception of uncertainty is more frightening than reality [18]. Understanding the prognosis can help patients to decide on further therapy, especially when they have to choose between life-extending therapy and comfort care [27]. However, the wish for full disclosure of prognosis of patients with advanced cancer is ambiguous: Some patients prefer full disclosure while others do not $[23,26,28]$. Considering their end of life, patients want to know if pain will be relieved and who will provide ongoing care [26]. However, information needs go far beyond medical issues as the cancer experience affects all dimensions of life, i.e. physical, emotional, social and spiritual aspects. Patients expressed the need to know how their disease will affect their everyday life and the lives of their family members, how to pay for their care, and how to write a will [26]. Family caregivers involved in end-of-life care at home have a great need to learn about the practical issues of caring for their loved one: They need to learn about medication and pain management, physical symptoms and comfort, nutrition, personal hygiene and excretion, positioning, technical equipment, availability of local support, and emergency measures [29]. Once they have accepted that death is inevitable, they address the need to learn more about the dying process [18].

\section{Process of Information: What is Valued as Helpful?}

The relationship and interaction between patient, family and health care professionals have considerable importance in finding out and meeting the patient's needs [22, 30]. Health care professionals are valued as the preferred source of information [20,21]. Patients and families value the process of information sharing as just as relevant as the content $[18,22]$. The way information was provided influenced subsequent conversations and the way information was perceived: If patients perceived a trusting relationship to their physicians in previous talks, they were more confident in consecutive visits, even with health care professionals they had not met before [22]. Patients specified requirements for sensitive information sharing: They wanted the health care providers to be honest $[22,26]$, to convey hope $[22,26]$, to speak in plain language [22], to be empathic [22], to give them enough time during the discussion [22] and to pace the amount of information to what they can assimilate [22]. 


\section{Patient Information to Enhance Self-Care}

Patients and families cannot anticipate the whole spectrum of information needed to manage illness and daily life. Their perspective on information needs should be the focus of attention, but must be completed by the health care professionals' point of view. One example is pain management. Many people have misconceptions about pain and pain management and avoid talking about pain because they are afraid of taking pain killers [31, 32]. They need to know about modern pain management strategies to make better use of pain therapy and to participate actively $[33,34]$. Orem's Self-Care Theory can serve as a theoretical framework to define patient information needs $[35,36]$. Orem proposed that individuals in principle are able and willing to initiate and perform self-care to maintain life, health and well-being [35]. However, illness or therapy can change self-care demands, and the patient may need appropriate information and training to fulfill these demands [35]. Research shows that patients who received special education can improve their self-care activities and develop more effective strategies to successfully manage therapeutic side effects, pain and other burdening symptoms [37-39].

\section{Shortcomings}

Although the importance of providing professional patient information has been recognized for many years, the quality of information-giving still requires improvement. Deficits are most prominent in the following areas of information giving.

\section{Structure}

As far as 'structure' is concerned, transsectoral health care delivery, specialization and lack of continuity throughout the cancer care continuum impede a trusted relationship between health care professionals and patients. The resulting loss of information bears the risk of patients falling through the cracks. Lack of resources, like time constraints [40] and scarcities in formal training of health care professionals, directly affect the clinician-patient encounter. So far, lack of formal assignment of patient information, i.e. defining roles and responsibility of health care professionals, planning, and documenting needs assessment, has led to a rather ad hoc, unsystematic patient information process. Asymmetry of information and knowledge and the health care professionals' dominance impede successful information sharing and shared decision making. In this context, the use of the concept 'informed consent' is questionable.

\section{Process}

The process of providing patient information has been described as not effective in several ways. Health care professionals tend to ask inhibitory instead of facilitative questions. Open questions which encourage and enable the patient to disclose his concerns are often avoided [41]. Physicians employ a rather medico-professional-oriented terminology that is difficult to understand for many patients [40, 42]. Moreover, physicians rarely check what patients have understood [43]. Patients withhold their concerns and questions because of lack of time [40] and interviewing style: If health care professionals do not explicitly prompt the patients to talk about emotional and social issues, the patients will not expect that the physicians are responsible for these issues and retain their worries [24]. Therefore, many patient concerns remain hidden and needs remain unmet, not only in the inpatient chemotherapy setting [44] but even in the hospice setting [24]. Additionally, physicians are rather reluctant to offer information on prognosis, especially in advanced cancer [25].

\section{Strategies for Improvement}

We now discuss strategies for improvement relating to optimizing the structure of health care service and improving the process of information-giving.

\section{Structure}

Structure comprises health care policies, rules and legislations, management strategies of health care services, infrastructure, workflow management, formal and informal teaching programs, and allocation of resources. The World Health Organization [45] proposed standards for hospitals to establish patient information within the concept of Health Promotion that can serve as a template to improve structure on the organizational basis. They specify the organizations' responsibility to stipulate a management policy for health promotion activities, to identify responsibilities and to allocate resources, in order to ensure competencies of staff and patient information throughout the care pathway and after discharge [45]. A manual is available to guide implementation and evaluation of these standards [46].

\section{Process}

Characteristics of the process of information-giving relate to the way it is performed, i.e. where and when it takes place, who delivers the information, and what methods (i.e. personal communication styles, leaflets, patient/proxy workshops) of communication are employed. Within this scenario, the interaction of health care professionals with patients and families is a pivotal element as it significantly affects their emotional response, understanding and coping. More engagement in face-to-face communication is recommended by national commissions (Sachverständigenrat für die Konzertierte Aktion im Gesundheitswesen, National Institute for Clinical Excellence, National Cancer Institute [19, 47, 48]). Relevant features of information-sharing are (table 1): 'building a trustful relationship', 'supportive listening', 'effective interviewing', 'helping the patient to find out his priorities', 'helping the 
Table 1. Recommendations for effective patient information (based on $[3,5,18,19,22,41,49-54]$ )

\begin{tabular}{|c|c|}
\hline Building a trustful relationship & be honest \\
\hline \multirow[t]{5}{*}{ Supportive listening } & non-directive, person-centered, empathic approach \\
\hline & use open questions \\
\hline & be sensitive to the cues of the patient \\
\hline & help the patient to find out his priorities \\
\hline & encourage patients and families to express their questions and concerns \\
\hline $\begin{array}{l}\text { Actively address information needs concerning } \\
\text { prognosis and end-of-life issues }\end{array}$ & - \\
\hline \multirow[t]{2}{*}{ Help the patient to set priorities } & learn about the individual context and values \\
\hline & the best medical option is not necessarily what is in the best interest of the patient \\
\hline \multirow[t]{2}{*}{ Ensure understanding } & employ everyday language, avoid medical jargon \\
\hline & $\begin{array}{l}\text { accept that patients may not always be able to process information because he or she might } \\
\text { be emotionally overwhelmed or may suffer from symptom load or drug-induced restraint } \\
\text { constantly check what he or she understood and whether or not the information is perceived } \\
\text { as helpful } \\
\text { summarize the provided information to structure the conveyed message and point out results } \\
\text { of the conversation }\end{array}$ \\
\hline
\end{tabular}

patient to understand' and 'sharing power' $[3,5,18,19,22,41$, 49-54].

The patients' perception of a trustful relationship is one that is characterized as feeling connected, understood and acknowledged as well as being convinced that the clinician is committed to their best interest $[19,55]$. Supportive listening requires a non-directive, person-centered, empathic attitude and sensitivity to the cues of the patient [49]. Effective interviewing aims at encouraging patients and families to express their questions and concerns, as they need support especially when asking about prognosis and end-of-life issues [3]. Using open questions helps the patient to display his point of view and feelings and become more involved [41]. Eliciting psychosocial issues as well as physical complaints and cultural or socioeconomic aspects is necessary to understand the individual context [19, 41]. Learning about the individual context and values is a premise to help the patient find out his or her priorities. The best medical option is not necessarily what is in the best interest of the patient [51]. For example, if a patient is completely occupied with the management of social problems, like the care of his/her children or parents, he or she might decide against a certain medical regimen. Helping the patient to understand the necessary information and comprehend the available support requires employing everyday language and avoiding medical terminology, to avoid misunderstandings and an increase in the asymmetry of knowledge and power $[19,22,52]$. Cancer patients may not always be able to retain and process information because they may be emotionally overwhelmed [50] or impaired in their cognitive capability. Therefore, it is necessary to constantly check what they have understood and whether the information is helpful [18]. Summarizing information can organize and structure the conveyed message and point out results of the conversation. 'Sharing power' implies a participative approach, thus offering opportunities for patient participation at all stages of the disease [19].
Several tools are available to facilitate and ascertain information-giving during daily routine and throughout the cancer care continuum. Osse et al. from the Netherlands [56] developed a clinical tool that addresses informational needs of palliative care patients, including information about treatment possibilities and side effects, physical symptoms that can be expected, nourishment, alternative healing methods, sexuality, euthanasia (as it is relevant in the Netherlands because of the national legislation), agencies who provide help, and medical (e.g. technical) aids. This tool assesses problems with consultations, physical symptoms, and social and financial issues [56]. To assist the patients' and caregivers' enquiries during physician consultations, question prompt lists to propose potentially relevant questions to the patient have been valued as helpful by patients $[3,57,58]$. Two studies documented an increase in the number of questions asked during physician-patient or physician-caregiver encounters and an enhancement of discussions about end-of-life issues [3, 57].

Since many questions and concerns of patients deal with end-of-life issues, symptom relief, and patterns of decline, early integration of palliative care can provide a comprehensive approach to respond to psychosocial, physical, and spiritual information needs [59]. Research shows that patients who participated in early palliative care demand less aggressive therapy and report better symptom control and quality of life $[60,61]$. Thorough assessment of the patients' individual (information, physical, psychosocial, and spiritual) needs, values and priorities as well as an adequate response (open communication) to these needs may have contributed to these findings. 'Shared care' concepts with palliative care teams may also reduce caregiver burden and workload throughout the course of the disease since psychosocial care can be very demanding, especially in times of crisis. Palliative care offers support in coping throughout the cancer care continuum and can be integrated into all settings of care, i.e. in the community, at home, in nursing homes and hospitals [62]. 
To improve continuity and consistence of information throughout the care continuum and across disciplines, professions and settings, van Wersch et al. [9] developed a multidisciplinary care protocol for breast cancer patients that outlines information goals of each party involved. It was valued as useful by patients and health care providers to coordinate patient information and improve coherence throughout the entire course of care [9]. At the Center of Integrated Oncology (CIO) at the University Hospitals of Cologne and Bonn, a cross-sectional care protocol is being developed that identifies patient information needs and links them to the clinical care pathway. Information options that can be offered to patients at various stages of the care pathway include patient seminars, web-based center-specific care information, and information leaflets. The latter target various cancer topics and can increase knowledge and recall $[39,63]$. There is still little proof of acceptability and effectiveness of patient information leaflets in later stages of cancer. Print media, prompt lists and protocols are valuable when they assist the information process rather than replace interpersonal information [63, 64].

\section{Limitations}

Communication and information needs strongly depend on the cultural background [65]. The concepts presented in this review, however, mostly lack validation for the German language and culture. Moreover, as for other communicative and psychosocial interventions, randomized controlled trials or large cohort studies of the approaches discussed here are scarce. Therefore, the level of evidence to support the use of these concepts is limited.

\section{Conclusions}

Providing patient information throughout the process of the disease is an indispensable component of health care professionals' duties when caring for patients with cancer. The therapeutic merits that come along with successful patient-centered information cannot be underestimated (increase of the patients' quality of life and control, reduction of therapeutic side effects and unnecessary hospitalizations, etc.). Yet, individualized and thorough provision of information is challenging. Therefore, on the structural level, health care services should be better educated to ensure effective patient information and counseling throughout the care continuum. Apart from conveying such interactional skills, patient information may be enhanced by cooperation with administrative structures to provide written and/or online information, closely cooperating with a palliative care program that is integrated very early in the course of incurable progressive disease.

\section{Acknowledgements}

We thank the Dr. Werner Jackstädt Stiftung for funding. The scientific work of the Department of Palliative Medicine, University Clinic of Cologne, is supported by the Federal Ministry for Education and Science (BMBF 01KN0706). The clinical and academic activities of the Department of Palliative Medicine, University Clinic of Cologne, are substantially supported by the German Cancer Aid (Deutsche Krebshilfe e.V.).

\section{Disclosure Statement}

No competing financial interests exist.

\section{References}

$>_{1}$ Sanson-Fisher R, Girgis A, Boyes A, Bonevski B, Burton L, Cook P: The unmet supportive care needs of patients with cancer. Supportive Care Review Group. Cancer 2000;88:226-237.

2 Rainbird K, Perkins J, Sanson-Fisher R, Rolfe I, Anseline P: The needs of patients with advanced, incurable cancer. Br J Cancer 2009;101:759-764.

$\checkmark 3$ Clayton JM, Butow PN, Tattersall MH, Devine RJ, Simpson JM, Aggarwal G, Clark KJ, Currow DC, Elliott LM, Lacey J, Lee PG, Noel MA: Randomized controlled trial of a prompt list to help advanced cancer patients and their caregivers to ask questions about prognosis and end-of-life care. J Clin Oncol 2007;25:715-723.

$\checkmark 4$ Mistry A, Wilson S, Priestman T, Damery S, Haque M: How do the information needs of cancer patients differ at different stages of the cancer journey? A cross-sectional survey. JRSM Short Rep 2010;1:30.

5 Stewart MA: Effective physician-patient communication and health outcomes: A review. CMAJ 1995;152:1423-1433.
6 Uchida M, Akechi T, Okuyama T, Sagawa R, Nakaguchi T, Endo C, Yamashita H, Toyama T, Furukawa TA: Patients' supportive care needs and psychological distress in advanced breast cancer patients in Japan. Jpn J Clin Oncol 2010, in press.

7 Hancock K, Clayton JM, Parker SM, Walder S, Butow PN, Carrick S, Currow D, Ghersi D, Glare P, Hagerty R, Tattersall MH: Discrepant perceptions about end-of-life communication: A systematic review. J Pain Symptom Manage 2007;34:190200.

8 Dimoska A, Girgis A, Hansen V, Butow PN, Tattersall MH: Perceived difficulties in consulting with patients and families: A survey of Australian cancer specialists. Med J Aust 2008;189:612-615.

9 van Wersch A, Bonnema J, Prinsen B, Pruyn J, Wiggers T, van Geel AN: Continuity of information for breast cancer patients: The development, use and evaluation of a multidisciplinary careprotocol. Patient Educ Couns 1997;30:175-186.

10 Jenkins V, Fallowfield L, Saul J: Information needs of patients with cancer: Results from a large study in UK cancer centres. Br J Cancer 2001;84:48-51.
11 Cassileth BR, Zupkis RV, Sutton-Smith K, March V: Information and participation preferences among cancer patients. Ann Intern Med 1980;92:832-836.

12 Fallowfield L, Ford S, Lewis S: No news is not good news: Information preferences of patients with cancer. Psychooncology 1995;4:197-202.

13 Blanchard CG, Labrecque MS, Ruckdeschel JC, Blanchard EB: Information and decision-making preferences of hospitalized adult cancer patients. Soc Sci Med 1988;27:1139-1145.

14 Leydon GM, Boulton M, Moynihan C, Jones A, Mossman J, Boudioni M, McPherson K: Cancer patients' information needs and information seeking behaviour: In depth interview study. BMJ 2000;320:909-913.

15 Butow PN, Maclean M, Dunn SM, Tattersall MH, Boyer MJ: The dynamics of change: Cancer patients' preferences for information, involvement and support. Ann Oncol 1997;8:857-863.

16 Innes S, Payne S: Advanced cancer patients' prognostic information preferences: A review. Palliat Med 2009;23:29-39. 
17 Folkman S, Lazarus RS, Dunkel-Schetter C, DeLongis A, Gruen RJ: Dynamics of a stressful encounter: Cognitive appraisal, coping, and encounter outcomes. J Pers Soc Psychol 1986;50:9921003.

18 Rose KE: A qualitative analysis of the information needs of informal carers of terminally ill cancer patients. J Clin Nurs 1999;8:81-88.

19 Epstein R, Street RL, Jr: Patient-centered communication in cancer care: Promoting healing and reducing suffering. http://outcomes.cancer.gov/areas/ pcc/communication/pcc_monograph.pdf, accessed 2010-12-13.

20 Rutten LJ, Arora NK, Bakos AD, Aziz N, Rowland J: Information needs and sources of information among cancer patients: A systematic review of research (1980-2003). Patient Educ Couns 2005;57:250-261.

21 Rees CE, Bath PA: The information needs and source preferences of women with breast cancer and their family members: A review of the literature published between 1988 and 1998. J Adv Nurs 2000;31:833-841.

22 Kirk P, Kirk I, Kristjanson LJ: What do patients receiving palliative care for cancer and their families want to be told? A Canadian and Australian qualitative study. BMJ 2004;328:1343.

-23 Elkin EB, Kim SH, Casper ES, Kissane DW, Schrag D: Desire for information and involvement in treatment decisions: Elderly cancer patients' preferences and their physicians' perceptions. J Clin Oncol 2007;25:5275-5280.

-24 Heaven CM, Maguire P: Disclosure of concerns by hospice patients and their identification by nurses. Palliat Med 1997;11:283-290.

25 Hancock K, Clayton JM, Parker SM, Wal der S, Butow PN, Carrick S, Currow D, Ghersi D Glare P, Hagerty R, Tattersall MH: Truth-telling in discussing prognosis in advanced life-limiting illnesses: A systematic review. Palliat Med 2007;21:507-517.

26 Kutner JS, Steiner JF, Corbett KK, Jahnigen DW, Barton PL: Information needs in terminal illness. Soc Sci Med 1999;48:1341-1352.

27 Weeks JC, Cook EF, O’Day SJ, Peterson LM, Wenger N, Reding D, Harrell FE, Kussin P, Dawson NV, Connors AF Jr, Lynn J, Phillips RS: Relationship between cancer patients' predictions of prognosis and their treatment preferences. JAMA 1998;279:1709-1714.

28 Butow PN, Dowsett S, Hagerty R, Tattersall MH: Communicating prognosis to patients with metastatic disease: What do they really want to know? Support Care Cancer 2002;10:161-168.

29 Bee P, Barnes P, Luker K: A systematic review of informal caregivers' needs in providing homebased end-of-life care to people with cancer. J Clin Nurs 2009;18:1379-1393.

-30 Rodin G, Mackay JA, Zimmermann C, Mayer C, Howell D, Katz M, Sussman J, Brouwers M: Clinician-patient communication: A systematic review. Support Care Cancer 2009;17:627-644.

-31 Oldenmenger WH, Sillevis Smitt PA, van Dooren S, Stoter G, van der Rijt CC: A systematic review on barriers hindering adequate cancer pain management and interventions to reduce them: A critical appraisal. Eur J Cancer 2009;45:1370-1380.

32 Ward S, Carlson-Dakes K, Hughes SH, Kwekkeboom KL, Donovan HS: The impact on quality of life of patient-related barriers to pain management. Res Nurs Health 1998;21:405-413.
33 Gaertner J, Voltz R: The cancer pain management plan. J Palliat Med 2010;13:95-96.

34 Strohbuecker B: Patientenschulung; in: Deutsches Netzwerk für Qualitätsentwicklung in der Pflege (ed): Expertenstandard Schmerzmanagement in der Pflege bei akuten oder tumorbedingten chronischen Schmerzen. Osnabrück, DNQP, 2005.

35 Orem DE: Nursing: Concepts of Practice. St. Louis, Mosby-Year Book, 1991.

36 Holler EM, Paulsen A: [Case Report: The practical use of the self-care deficit nursing theory for a patient with a neuroendocrine cancer of the duodenum]. Pflege 2010;23:5-11.

37 Devine EC: Effects of psychoeducational care for adult surgical patients: A meta-analysis of 191 studies. Patient Educ Couns 1992;19:129-142.

38 Miaskowski C, Dodd M, West C, Schumacher K, Paul SM, Tripathy D, Koo P: Randomized clinical trial of the effectiveness of a self-care intervention to improve cancer pain management. J Clin Oncol 2004:22:1713-1720.

39 Devine EC, Westlake SK: The effects of psychoeducational care provided to adults with cancer: Meta-analysis of 116 studies. Oncol Nurs Forum 1995;22:1369-1381.

40 Yardley SJ, Davis CL, Sheldon F: Receiving a diagnosis of lung cancer: Patients' interpretations, perceptions and perspectives. Palliat Med 2001;15:379-386.

41 Maguire P, Faulkner A, Booth K, Elliott C, Hillier $\mathrm{V}$ : Helping cancer patients disclose their concerns. Eur J Cancer 1996;32A:78-81.

42 Symmers WSC: 'Explain in simple words - ensure the words are understood'. BMJ 1995;310:1178.

43 Tattersall MH, Gattellari M, Voigt K, Butow PN: When the treatment goal is not cure: Are patients informed adequately? Support Care Cancer 2002;10:314-321.

44 Farrell C, Heaven C, Beaver K, Maguire P: Identifying the concerns of women undergoing chemotherapy. Patient Educ Couns 2005;56:72-77.

45 World Health Organization Europe: Standards for health promotion in hospitals. WHO, 2004.

46 World Health Organization: Implementing health promotion in hospitals: Manual and self-assessment forms. WHO, 2006

47 Sachverständigenrat für die konzertierte Aktion im Gesundheitswesen: Bedarfsgerechtigkeit und wirtschaftlichkeit, Bd. 1: Zielbildung, Prävention, Nutzerorientierung und Partizipation. http://dipbt. bundestag.de/doc/btd/14/056/1405661.pdf, accessed 2010-12-13.

48 National Institute for Clinical Evidence: Improving Supportive and Palliative Care for Adults with Cancer. The Manual. www.nice.org.uk/nicemedial live/10893/28816/28816.pdf.

49 Rogers C: Client Centered Therapy. Boston, Houghton Mifflin, 1951.

50 van der Molen B: Relating information needs to the cancer experience. 2. Themes from six cancer narratives. Eur J Cancer Care (Engl) 2000;9:48-54.

51 Coy JA: Autonomy-based informed consent: Ethical implications for patient noncompliance. Phys Ther 1989;69:826-833.

52 Doak CC, Doak LG, Friedell GH, Meade CD: Improving comprehension for cancer patients with low literacy skills: Strategies for clinicians. CA Cancer J Clin 1998;48:151-162.
3 Walling A, Lorenz KA, Dy SM, Naeim A, Sanati $\mathrm{H}$, Asch SM, Wenger NS: Evidence-based recommendations for information and care planning in cancer care. J Clin Oncol 2008;26:3896-3902.

54 Rodin G, Zimmermann C, Mayer C, Howell D, Katz M, Sussman J, Mackay JA, Brouwers M: Clinician-patient communication: Evidence-based recommendations to guide practice in cancer. Curr Oncol 2009;16:42-49.

55 Parker SM, Clayton JM, Hancock K, Walder S, Butow PN, Carrick S, Currow D, Ghersi D, Glare P, Hagerty R, Tattersall MH: A systematic review of prognostic/end-of-life communication with adults in the advanced stages of a life-limiting illness: Patient/caregiver preferences for the content, style, and timing of information. J Pain Symptom Manage 2007;34:81-93.

56 Osse BH, Vernooij MJ, Schade E, Grol RP: Towards a new clinical tool for needs assessment in the palliative care of cancer patients: The PNPC instrument. J Pain Symptom Manage 2004;28:329_ 341.

57 Hebert RS, Schulz R, Copeland VC, Arnold RM Pilot testing of a question prompt sheet to encourage family caregivers of cancer patients and physicians to discuss end-of-life issues. Am J Hosp Palliat Care 2009;26:24-32.

58 Bruera E, Sweeney C, Willey J, Palmer JL, Tolley S, Rosales M, Ripamonti C: Breast cancer patient perception of the helpfulness of a prompt sheet versus a general information sheet during outpatient consultation: A randomized, controlled trial. J Pain Symptom Manage 2003;25:412-419.

59 Gaertner J, Wolf J, Scheicht D, Frechen S, Klein U, Hellmich M, Ostgathe C, Hallek M, Voltz R Implementing WHO recommendations for palliative care into routine lung cancer therapy: A feasibility project. J Palliat Med 2010;13:727-732.

60 Wright AA, Zhang B, Ray A, Mack JW, Trice E, Balboni T, Mitchell SL, Jackson VA, Block SD, Maciejewski PK, Prigerson HG: Associations between end-of-life discussions, patient mental health, medical care near death, and caregiver bereavement adjustment. JAMA 2008;300:1665-1673.

61 Temel JS, Greer JA, Muzikansky A, Gallagher ER, Admane S, Jackson VA, Dahlin CM, Blinderman CD, Jacobsen J, Pirl WF, Billings JA, Lynch TJ: Early palliative care for patients with metastatic non-small-cell lung cancer. N Engl J Med 2010;363:733-742.

62 World Health Organization: Cancer control: Knowledge in action. WHO guide for effective programmes, palliative care, module 5. www.who. int/cancer/media/FINAL-PalliativeCareModule. $p d f$, accessed 2010-12-13.

63 McPherson CJ, Higginson IJ, Hearn J: Effective methods of giving information in cancer: A systematic literature review of randomized controlled trials. J Public Health Med 2001;23:227-234.

64 Coulter A, Ellins J: Effectiveness of strategies for informing, educating, and involving patients. BMJ 2007;335:24-27.

65 Mystakidou K, Parpa E, Tsilila E, Katsouda E, Vlahos L: Cancer information disclosure in different cultural contexts. Support Care Cancer 2004;12:147-154. 